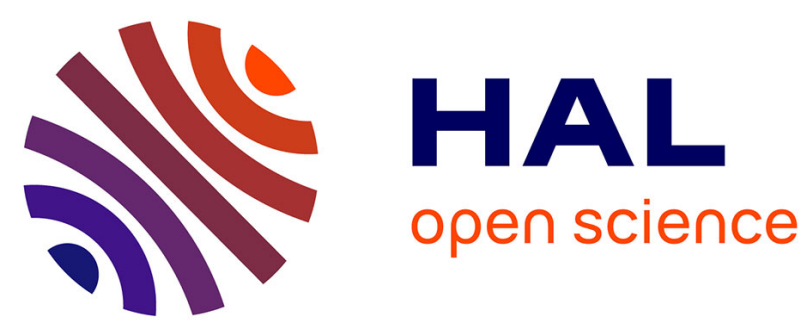

\title{
A new approach to grafting a monolayer of oriented Mn12 nanomagnets on silicon
}

Benoit Fleury, Laure Catala, V. Huc, Christophe David, Wang Zhao Zhong, Pascale Jégou, Laurent Baraton, Serge Palacin, Pierre-Antoine Albouy, Talal Mallah

\section{To cite this version:}

Benoit Fleury, Laure Catala, V. Huc, Christophe David, Wang Zhao Zhong, et al.. A new approach to grafting a monolayer of oriented Mn12 nanomagnets on silicon. Chemical Communications, 2005, pp.2020-2022. 10.1039/b419271k . cea-01056649

\section{HAL Id: cea-01056649 https://hal-cea.archives-ouvertes.fr/cea-01056649}

Submitted on 20 Aug 2014

HAL is a multi-disciplinary open access archive for the deposit and dissemination of scientific research documents, whether they are published or not. The documents may come from teaching and research institutions in France or abroad, or from public or private research centers.
L'archive ouverte pluridisciplinaire HAL, est destinée au dépôt et à la diffusion de documents scientifiques de niveau recherche, publiés ou non, émanant des établissements d'enseignement et de recherche français ou étrangers, des laboratoires publics ou privés. 


\title{
A new approach to grafting a monolayer of oriented $\mathrm{Mn}_{12}$ nanomagnets on silicon $\dagger$
}

\author{
Benoit Fleury, ${ }^{a}$ Laure Catala, ${ }^{a}{ }^{a}$ Vincent Huc, ${ }^{a}$ Christophe David, ${ }^{b}$ Wang Zhao Zhong, ${ }^{b}$ Pascale Jegou, ${ }^{c}$ \\ Laurent Baraton, ${ }^{c}$ Serge Palacin, ${ }^{c}$ Pierre-Antoine Albouy ${ }^{d}$ and Talal Mallah*a
}

Received (in Cambridge, UK) 24th December 2004, Accepted 8th February 2005

First published as an Advance Article on the web 25th February 2005

DOI: $10.1039 / \mathrm{b} 419271 \mathrm{k}$

The functionalisation of a $\mathrm{Si}(100)$ silicon wafer allows for the oriented grafting of a monolayer of $\mathrm{Mn}_{12}$ nanomagnets using a two-step procedure.

The discovery of the blocking and the quantum tunnelling of the magnetization in molecular systems was a major breakthrough in the area of molecular magnetism. ${ }^{1}$ The first complex where these phenomena were observed is $\left[\mathrm{Mn}_{12} \mathrm{O}_{12}\left(\mathrm{CH}_{3} \mathrm{COO}\right)_{16}\left(\mathrm{H}_{2} \mathrm{O}\right)_{4}\right]$ $\left(\mathrm{Mn}_{12}\right.$-ac), described by Lis in $1980 .^{2}$ The blocking of magnetization is due to the high spin ground state of the molecule $(S=10)$ and the uniaxial magnetic anisotropy responsible for a relatively high barrier to the reorientation of the magnetization below $8 \mathrm{~K}^{3}$ Such behaviour leads to a magnetic bistability that may be utilised to store information (even if it occurs below $4 \mathrm{~K}$ in the case of $\mathrm{Mn}_{12}$ derivatives), where a bit of information has the size of one molecule (around $1.2 \mathrm{~nm}$ ).

One of the very first steps for reaching such a goal is to organize the molecules as a monolayer on a substrate in order to address a single molecule. Different approaches have been reported recently: (i) using the Langmuir-Blodgett technique; ${ }^{4}$ (ii) grafting on a gold substrate by using a thiol modified $\mathrm{Mn}_{12}$ complex; ${ }^{5}$ (iii) deposition of the biphenyl derivative of $\mathrm{Mn}_{12}$ and nanopatterning on polycarbonate films; ${ }^{6}$ and (iv) deposition of monolayer and multilayers on gold. ${ }^{7}$ Very recently, grafting $\mathrm{Mn}_{12}$-ac on $\mathrm{Si}(100)$ has been reported. ${ }^{8}$

$\uparrow$ Electronic supplementary information (ESI) available: Spectroscopic data of deposited and grafted Mn12 sample (Figs. S1-S6). See http:// www.rsc.org/suppdata/cc/b4/b419271k/

*laurecatala@icmo.u-psud.fr (Laure Catala)

mallah@icmo.u-psud.fr (Talal Mallah)

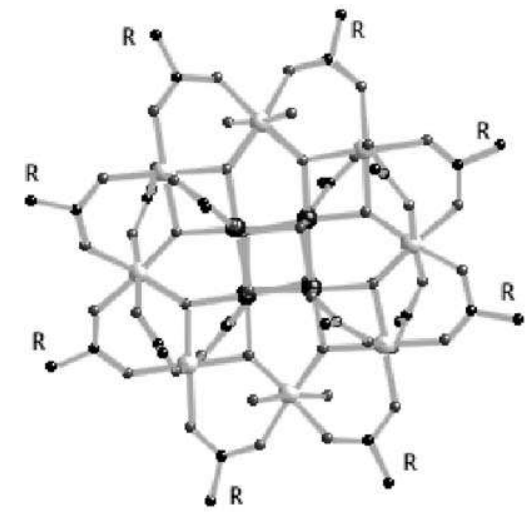

The next step is to conceive an approach where grafting leads to an orientation of the molecules on the substrate. We show here that by using a mixed $\mathrm{Mn}_{12}$ complex (i.e. containing two different carboxylate groups) it is possible to graft a monolayer in an oriented manner on a silicon substrate. $\mathrm{Mn}_{12}$-ac is made of a $\mathrm{Mn}_{12} \mathrm{O}_{12}(4 \mathrm{Mn}(\mathrm{IV})$ and $8 \mathrm{Mn}(\mathrm{III}))$ core which has a disk-like shape surrounded by 16 acetate groups: 8 in equatorial and 8 in axial positions and 4 water molecules (see Scheme 1).

The Mn(III)-O long distances (Jahn-Teller effect) are those with the axial ligands. Christou and co-workers elegantly demonstrated that due to $\mathrm{p} K_{\mathrm{a}}$ differences between carboxylic acids it is possible (i) to substitute the acetate groups by other carboxylates in solution keeping the oxide core intact, and (ii) to prepare mixed complexes from the selective substitution of the axial or the equatorial carboxylates. ${ }^{9,10}$ We took advantage of this particular reactivity and selected a $\mathrm{Mn}_{12}$ complex possessing dichloroacetate groups in axial positions and tert-butyl acetate groups in equatorial positions, i.e. $\mathrm{Mn}_{12} \mathrm{O}_{12}\left(\mathrm{CHCl}_{2} \mathrm{COO}\right)_{8}\left(\mathrm{tBuCH}_{2} \mathrm{COO}\right)_{8}\left(\mathrm{H}_{2} \mathrm{O}\right)_{3}(\mathbf{1}) .{ }^{10}$ t Reacting 1 with a carboxylic acid-functionalised silicon wafer induces a selective substitution of either axial or equatorial carboxylates of the molecule by carboxylic acid groups originating from the substrate. The choice of axial chlorinated carboxylates allows to probe the ligands exchange by X-ray photoelectron spectroscopy (XPS).

Direct immersion of a $\mathrm{Si}-\mathrm{H}(100)$ surface $\$$ in neat distilled undecylenic acid $\left(110^{\circ} \mathrm{C}, 12 \mathrm{~h}\right.$ under Ar) leads to thermal grafting of the acid via its alkene end. ${ }^{11,12}$ The hypothesis of formation of silyl esters emitted in the case of this coupling agent, was discarded by complementary experiments. ${ }^{13}$ Attenuated transmission reflection infra-red (ATR-FTIR) spectroscopy shows that most of the available $\mathrm{Si}-\mathrm{H}$ functions have reacted as the intensity of the

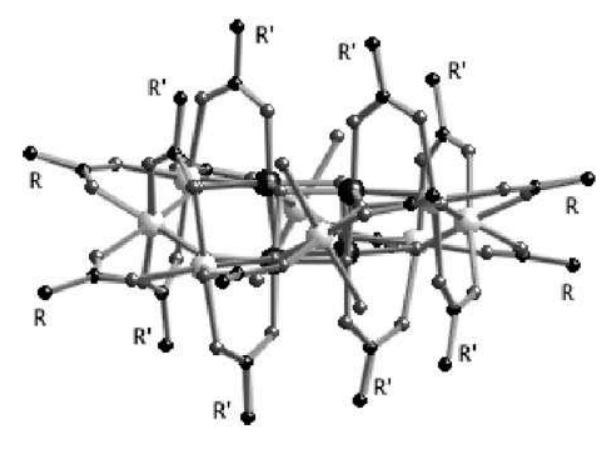

Scheme 1 
$2111 \mathrm{~cm}^{-1}$ peak (Si-H stretching vibrations) decreased (see ESI). $\dagger$ Indeed, only $50 \%$ of the $\mathrm{Si}-\mathrm{H}$ functions may react for steric reasons. ${ }^{14}$ Furthermore, the spectrum showed the presence of methylene stretching vibrations at 2855 and $2927 \mathrm{~cm}^{-1}$ (see ESI) $\dagger$ as well as the carbonyl stretching of the carboxylic acid at $1718 \mathrm{~cm}^{-1}$ (see ESI). $\dagger$ No C-H vibration due to terminal alkene groups could be observed, thus ascertaining the absence of grafting via silyl ester groups.

Grafting of $\mathbf{1}$ was achieved by immersion of the previous modified substrate in a degassed $10^{-4} \mathrm{M}$ toluene solution of the complex for $1 \mathrm{~h}$. The obtained wafer was thoroughly sonicated three times $(3 \times 10 \mathrm{~min})$ in $30 \mathrm{ml}$ of distilled toluene to remove any physisorbed molecules. ATR-FTIR spectra show that the band at $1718 \mathrm{~cm}^{-1}$ almost vanishes after the immersion of the substrate in the $\mathrm{Mn}_{12}$ solution which is the first evidence for the grafting of molecules by carboxylate substitution (see ESI). $\dagger$

XPS studies were carried out $\|$ on: (i) native silica where free molecules of 1 were merely deposited by evaporation of a droplet $\left(10^{-3} \mathrm{M}\right.$ in toluene) on the substrate to serve as a reference; (ii) the acid-functionalised $\mathrm{Si}(100)$ substrate with grafted $\mathrm{Mn}_{12}$. The XPS spectra of the references show all the expected characteristics (see binding energies in Table 1) already reported elsewhere. ${ }^{15}$ The Mn2p spectrum has two peaks at 653.8 and $642.2 \mathrm{eV}$, corresponding to the excitation from the $2 \mathrm{p}_{1 / 2}$ and $2 \mathrm{p}_{3 / 2}$ levels, respectively. Since the $\mathrm{Mn} 2 \mathrm{p}$ excitations are generally not sensitive to the oxidation state of the Mn atoms, the Mn3s spectrum was registered (native silica). The spectra obtained for the grafted $\mathrm{Mn}_{12}$ sample reveal the same features as the reference sample (Table 1). The energy difference $(\Delta E)$ between the Mn3s peaks of the reference and the grafted sample are equal to 5.4 and $5.5 \mathrm{eV}$, respectively (Fig. 1), close to the value reported for manganites with the average oxidation state of 3.3. ${ }^{16}$ This is the best evidence for the integrity of the grafted complex.

The ATR-FTIR and XPS data insure that $\mathbf{1}$ has been grafted on the substrate but do not give evidence that the sample analyzed is a monolayer of $\mathrm{Mn}_{12}$ molecules (some physisorbed molecules may be present on top of the first grafted monolayer despite the sonication process). In order to give such a proof we performed two additional studies. The first one consists in repeating exactly the same chemical process used for the grafting experiment on a substrate functionalised by undecane instead of undecanoic acid (i.e., carboxylic groups from the surface were replaced by methyl groups). The XPS spectra of a sample obtained without the sonication process show all the signals expected for $\mathrm{Mn}_{12}$

Table 1 Binding energies (eV) obtained from X-ray photoelectron spectroscopy

\begin{tabular}{|c|c|c|c|}
\hline & Peaks attribution & Deposited $\mathrm{Mn}_{12}{ }^{a}$ & Grafted $\mathrm{Mn}_{12}$ \\
\hline \multirow[t]{2}{*}{$\mathrm{O} 1 \mathrm{~s}$} & $\mathrm{COO}-/ \mathrm{COOH}$ & 532.0 & 532.0 \\
\hline & $\mathrm{Mn}-\mathrm{O}$ & 530.3 & 530.0 \\
\hline \multirow[t]{3}{*}{$\mathrm{C} 1 \mathrm{~s}$} & $\mathrm{CH}_{2}, \mathrm{CH}_{3}$ & 284.3 & 284.5 \\
\hline & $\mathrm{C}-\mathrm{Cl}$ & 287.6 & 287.6 \\
\hline & $\mathrm{C} \cdots \mathrm{O}$ & 288.7 & 288.8 \\
\hline \multirow[t]{2}{*}{$\mathrm{Cl} 2 \mathrm{p}$} & $2 \mathrm{p}_{1 / 2}$ & 201.8 & 201.9 \\
\hline & $2 \mathrm{p}_{3 / 2}$ & 200.2 & 200.3 \\
\hline \multirow[t]{2}{*}{$\operatorname{Mn} 2 p$} & $2 \mathrm{p}_{1 / 2}$ & 654.6 & 653.8 \\
\hline & $2 \mathrm{p}_{3 / 2}$ & 642.8 & 642.2 \\
\hline $\operatorname{Mn3s}(\Delta E)$ & 3s multiplet & $5.4 \mathrm{eV}$ & $5.5 \mathrm{eV}$ \\
\hline
\end{tabular}

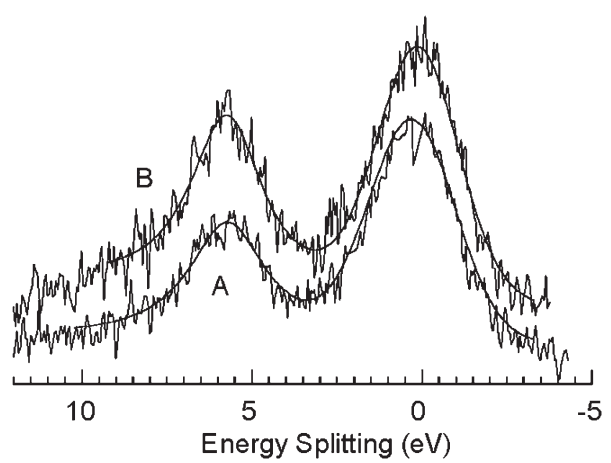

Fig. 1 Energy splitting of the Mn3s multiplet for deposited $\mathrm{Mn}_{12}$ on native silica (A) and grafted on $\mathrm{Si}(100)(\mathrm{B})$.

demonstrating that the molecules can be physisorbed. However, after sonicating the substrate no XPS signal is present anymore. This is the best evidence that sonication leads to the complete removal of physisorbed molecules while molecules linked by coordination bonds are still present. Thus, only one monolayer of $\mathbf{1}$ is present on the acid functionalised $\mathrm{Si}$ substrate. The definitive evidence comes from X-ray reflectivity studies before and after the grafting of the $\mathrm{Mn}_{12}$. From the surface electronic density modification observed by X-ray reflectivity, we deduced an average value of $1.5 \mathrm{~nm}$ for the thickness of the $\mathrm{Mn}_{12}$ layer. (see ESI) $\dagger$

Atomic force microscopy (AFM) imaging was performed on the acid functionalised and on the $\mathrm{Mn}_{12}$ grafted substrates (Fig. 2).** Fig. 2 shows that the average roughness of the acid functionalised $\mathrm{Si}$ substrate is lower than $0.5 \mathrm{~nm}$ on a large scale which is consistent with a very flat organic monolayer.

For the $\mathrm{Mn}_{12}$ grafted substrate, the topological image shows a homogeneous layer on a large scale (see ESI) $\dagger$ with a roughness between 1 and $1.5 \mathrm{~nm}$. One cannot exclude that the tip measures a thickness corresponding to the length of the organic layer and the grafted $\mathrm{Mn}_{12}$. Indeed, the presence of the $\mathrm{Mn}_{12}$ monolayer may well perturb the underlying organic part and create some holes.

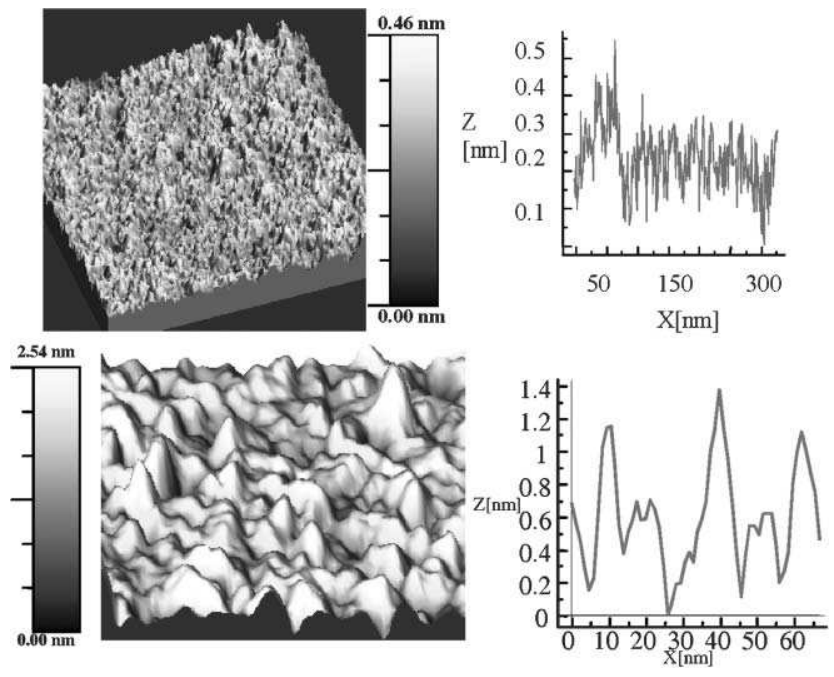

Fig. 2 (Top) AFM image $(400 \times 400 \mathrm{~nm})$ of grafted undecanoic acid on $\mathrm{Si}(100)$ wafer and topological profile, $($ down $)$ AFM image $(70 \times 70 \mathrm{~nm})$ of grafted $\mathrm{Mn}_{12}$ on $\mathrm{Si}(100)$ wafer and topological profile. 
In order to check the orientation of the grafted molecules, a quantitative analysis of the Mn2p and the Cl2p XPS signals was performed. The $\mathrm{Mn} / \mathrm{Cl}$ ratios extracted from the XPS data (see ESI) $\uparrow$ provide information on the nature of the substituted carboxylates: $\dagger \dagger$ if only equatorial tert-butyl acetates were exchanged upon grafting on the acid-functionalised $\mathrm{Si}$ surface, no difference in the $\mathrm{Mn} / \mathrm{Cl}$ ratio should be observed between the free and grafted $\mathrm{Mn}_{12}$ clusters (theoretical value $\mathrm{Mn} / \mathrm{Cl}=0.75$ ), whereas axial substitution should lead to a minimum of four remaining dichloroacetates $(\mathrm{Mn} / \mathrm{Cl}=1.5)$ out of the eight present on the non-grafted cluster. If substitution occurred in a random way, an average value of 6 remaining dichloroacetates would be expected, thus leading to a ratio $\mathrm{Mn} / \mathrm{Cl}=1$. Hence, the value of $\mathrm{Mn} / \mathrm{Cl}=0.74 \pm 0.04$ obtained on the grafted substrate means that the substitution proceeds only through replacement of equatorial tert-butyl acetate groups. Such a result may be at a first glance surprising because one may expect a substitution of the axial carboxylate groups less tightly linked to the $\mathrm{Mn}$ atoms because of the Jahn-Teller effect. However, this cannot actually be the case because the substrate is functionalised by carboxylic acid groups and not carboxylate groups. As already stated by Christou, ${ }^{10}$ the driving force of the reaction is the formation of the weakest acid, hence tert-butylacetic acid rather than dichloroacetic acid. Furthermore, the thermodynamically most stable bonds should form, i.e. those corresponding to the strongest $\mathrm{Mn}$-carboxylate bonds which are the equatorial ones where no Jahn-Teller effect is present.

In this communication, we have shown the feasibility of grafting on a large scale a homogenous monolayer of $\mathrm{Mn}_{12}$ derivative on silicon even though no lateral organisation could be observed. The $\mathrm{Mn} / \mathrm{Cl}$ elements ratios obtained from the analysis of the XPS spectra are in line with a preferred orientation of the $\mathrm{Mn}_{12}$ molecules with their anisotropy axes parallel to the substrate's surface. This is the first example which shows that orientation of the molecules may be achieved by chemical means. The next step is mastering the orientation of the $\mathrm{Mn}_{12}$ molecules with their anisotropy axes perpendicular to the 2D substrate.

We thank the CNRS (Centre National de la Recherche Scientifique), the French programme Nanosciences (ACI NANOMAG N45-01), and the European community for financial support (Contract MRTN-CT-2003-504880/RTN Network "QuEMolNa”).

Benoit Fleury, ${ }^{a}$ Laure Catala, ${ }^{* a}$ Vincent Huc, ${ }^{a}$ Christophe David, ${ }^{b}$ Wang Zhao Zhong, ${ }^{b}$ Pascale Jegou, ${ }^{c}$ Laurent Baraton, ${ }^{c}$ Serge Palacin, ${ }^{c}$ Pierre-Antoine Albouy ${ }^{d}$ and Talal Mallah ${ }^{* a}$

${ }^{a}$ Laboratoire de Chimie Inorganique, UMR CNRS 8613, Université Paris-Sud, 91405 Orsay, France.E-mail: laurecatala@icmo.u-psud.fr; mallah@icmo.u-psud.fr; Fax: (+33) (0)1 691547 54;

Tel: (+33) (0)169154749

${ }^{b}$ Laboratoire de Photonique et de Nanostructures, CNRS, route de Nozay, 91460 Marcoussis, France

${ }^{c}$ Chimie des Surfaces et Interfaces, CEAIDRECAM, CEA-Saclay, 91191 Gif sur Yvette, France

${ }^{d}$ Laboratoire de Physique des Solides, Bâtiment 510, Université de Paris-Sud, F-91405 Orsay Cedex, France

\section{Notes and references}

t NMR studies in solution show species where equatorial and axial carboxylates have been exchanged. The main species in solution is $\mathbf{1}$, since the axial tert-butyl resonances are so relatively weak compared to the equatorial tert-butyl resonance.

$\S$ Generation of the $\mathrm{Si}-\mathrm{H}$ functions proceeds through etching the wafers in a piranha bath $\left(30 \% \mathrm{H}_{2} \mathrm{O}_{2} / 70 \% \mathrm{H}_{2} \mathrm{SO}_{4}, 20 \mathrm{~min}, 120^{\circ}\right)$ followed by immersion in a $10 \% \mathrm{HF}$ solution. This procedure is repeated three times.

- $\mathrm{Mn}_{12} \mathrm{O}_{12}\left(\mathrm{CHCl}_{2} \mathrm{COO}\right)_{8}\left(t \mathrm{BuCH}_{2} \mathrm{COO}\right)_{8}\left(\mathrm{H}_{2} \mathrm{O}\right)_{3}$ was synthesized as previously described ${ }^{10}$ and single crystals, checked by X-ray diffraction and elemental analysis, were used in all experiments.

|| XPS spectra were recorded on a Vacuum Generator ESCALAB 210 using an $\mathrm{Al} \mathrm{K} \alpha$ source monochromatized at $1486.6 \mathrm{eV}$. The radiations were generated $(20 \mathrm{~mA}, 15 \mathrm{kV})$ under UHV at $10^{-10}$ mbar. Spectra were recorded at a take-off angle of $90^{\circ}$ with respect to the sample plane.

** Lateral resolution is limited by the curvature of the tip ( $2 \mathrm{~nm}$ curvature at the apex). The AFM images were taken in tapping mode (Nanoscope III, Si supersharp tip, Nanosensor at a resonance frequency of $236 \mathrm{KHz}$ ). $\dagger \mathrm{Mn} / \mathrm{Cl}$ ratios were calculated using the $\mathrm{Mn} 2 \mathrm{p}_{3 / 2}$ spectrum because of much better $\mathrm{S} / \mathrm{N}$ ratio. The reproducibility of all experiments has been checked (see ESI).†

1 L. Thomas, L. Lionti, R. Ballou, D. Gatteschi, R. Sessoli and B. Barbara, Nature, 1996, 383, 145; R. Sessoli, D. Gatteschi, A. Caneschi and M. A. Novak, Nature, 1993, 365, 141; R. Sessoli and D. Gatteschi, Angew. Chem., Int. Ed., 2003, 42, 268, and references therein.

2 T. Lis, Acta Crystallogr., 1980, B36, 2042.

3 A. Caneschi, D. Gatteschi, R. Sessoli, A. L. Barra, L. C. Brunel and M. Guillot, J. Am. Chem. Soc., 1991, 113, 5873.

4 M. Clemente-León, H. Soyer, E. Coronado, C. Mingotaud, C. J. GómezGarcia and P. Delhaès, Angew. Chem., Int. Ed., 1998, 37, 2842.

5 A. Cornia, A. C. Fabretti, M. Pacchioni, L. Zobbi, D. Bonacchi, A. Caneschi, D. Gatteschi, R. Biagi, U. Del Pennino, V. Valentina De Renzi, L. Gurevich and H. S. J. Van der Zant, Angew. Chem., Int. Ed., 2003, 42, 1642.

6 D. Ruiz Molina, M. Mas Torrent, A. I. Balana, N. Domingo, J. Tejada, M. T. Martinez, C. Rovira and J. Veciana, Adv. Mater., 2003, 15, 42; M. Cavallini, F. Biscarini, J. Gomez-Segura, D. Ruiz and J. Veciana, Nano Lett., 2003, 3, 1527.

7 J. S. Steckel, N. S. Persky, C. R. Martinez, C. L. Barnes, E. A. Fry, J. Kulkarni, J. D. Burgess, R. B. Pacheco and S. L. Stoll, Nano Lett., 2004, 4, 399.

8 G. G. Condorelli, A. Motta, I. L. Fragala, F. Giannazzo, V. Raineri, A. Caneschi and D. Gatteschi, Angew. Chem., Int. Ed., 2004, 43, 4081.

9 P. Artus, C. Boskovic, J. Yoo, W. E. Streib, L-C. Brunel, D. N. Hendrickson and G. Christou, Inorg. Chem., 2001, 40, 4199.

10 M. Soler, P. Artus, K. Folting, J. C. Huffman, D. N. Hendrickson and G. Christou, Inorg. Chem., 2001, 40, 4902; N. E. Chakov, W. Wernsdorfer, K. A. Abboud, D. N. Hendrickson and G. Christou, Dalton Trans., 2003, 2243.

11 J. M. Buriak, Chem. Rev., 2002, 102, 5, 1271 and references therein.

12 A. B. Sieval, A. L. Demirel, J. W. M. Nissink, M. R. Linford, J. H. Van der Maas, W. H. de Jeu, H. Zuilhof and E. J. R. Sudhölter, Langmuir, 1998, 14, 1759.

13 R. Boukherroub, J. T. C. Wojtyk, D. D. M. Wayner and D. J. Lockwood, J. Electrochem. Soc., 2002, 149, H59.

14 A. B. Sieval, V. van den Hout, H. Zuilhof and E. J. R. Sudhölter, Langmuir, 2001, 17, 2972.

15 J. S. Kang, J. H. Kim, Y. J. Kim, W. S. Jeon, D. Y. Jung, S. W. Han, K. H. Kim, K. J. Kim and B. S. Kim, J. Korean Phys. Soc., 2002, 40, L402.

16 V. R. Galakhov, M. Demeter, S. Bartkowski, M. Neumann, N. A. Ovechkina, E. Z. Kurmaev, N. I. Lobachevskaya, Ya. M. Mukovskii, J. Mitchell and D. L. Ederer, Phys. Rev. B, 2002, 65, 113102; X. Wang, Q. Cui, Y. Pan and G. Zou, J. Alloys Compd., 2003, 354, 91. 